Case Report

\title{
Toxoplasma Encephalitis following Tandem Autologous Hematopoietic Stem Cell Transplantation: A Case Report and Review of the Literature
}

\author{
Vidya Kollu $\left(\mathbb{D},{ }^{1}\right.$ Margarida Magalhaes-Silverman, ${ }^{1}$ Guido Tricot $\mathbb{D}^{\mathbb{D}},{ }^{1}$ and Dilek Ince $\mathbb{D}^{2}$ \\ ${ }^{1}$ University of Iowa, Department of Internal Medicine, Divisions of Hematology, Oncology, \\ and Blood and Bone Marrow Transplant, Iowa City, IA, USA \\ ${ }^{2}$ University of Iowa, Department of Internal Medicine, Division of Infectious Diseases, Iowa City, IA, USA
}

Correspondence should be addressed to Vidya Kollu; vkollu@mcw.edu

Received 4 July 2018; Accepted 24 September 2018; Published 11 November 2018

Academic Editor: Antonella Marangoni

Copyright (C) 2018 Vidya Kollu et al. This is an open access article distributed under the Creative Commons Attribution License, which permits unrestricted use, distribution, and reproduction in any medium, provided the original work is properly cited.

Infection with Toxoplasma gondii is a rare but often fatal complication in hematopoietic stem cell transplantation (HSCT) recipients. Most cases have been reported in allogeneic (allo-) HSCT recipients, with only narrative reports following autologous HSCT (ASCT). We report the case of a 58-year-old Caucasian male presenting with toxoplasma encephalitis following tandem ASCT for myeloma and successfully treated with diagnosis by polymerase chain reaction analysis of cerebrospinal fluid. He was treated with sulfadiazine and pyrimethamine (with leucovorin) followed by pyrimethamine and atovaquone as secondary prophylaxis while receiving subsequent therapy for progressive multiple myeloma. Toxoplasmosis is a potential complication in allo-HSCT as well as ASCT recipients and should be considered in any post-HSCT patient with neurological dysfunction. Rapid diagnosis and immediate antimicrobial treatment are essential to avoid morbidity and mortality.

\section{Introduction}

Autologous HSCT (ASCT) is a pivotal therapeutic option for patients with multiple myeloma (MM) who are eligible for transplantation and achieve at least partial response after combination chemotherapy [1]. Tandem transplantation shows a higher overall survival and progression-free survival in $\mathrm{MM}$ when compared to patients who receive a single ASCT $[2,3]$. Despite the many advances in supportive care, infections continue to complicate the posttransplant course in many patients [4].

Infection with Toxoplasma gondii, is a rare but often fatal opportunistic infection in HSCT recipients. Most cases have been reported following allogeneic (allo-) HSCT especially in patients with severe graft versus host disease, requiring intensive immunosuppressive therapy $[5,6]$. However, there are reports of disseminated disease [7], retinochoroiditis [8], or solitary spinal cord lesion [9] following ASCT. Cerebral toxoplasmosis has been described in one case each following
ASCT for non-Hodgkin's lymphoma [10], neuroblastoma in a pediatric patient [11], and after tandem ASCT for myeloma [12]. We report the case of a 58-year-old Caucasian male with toxoplasma encephalitis following tandem ASCT for multiple myeloma.

\section{Case Report}

2.1. Clinical Summary. A 58-year-old Caucasian male was diagnosed in early 2014 with multiple myeloma. He was treated with dexamethasone, cisplatin, doxorubicin, cyclophosphamide, and etoposide-induction chemotherapy and then tandem ASCT in June and September 2014, respectively. Pretransplant chemotherapy consisted of bortezomib, dexamethasone, thalidomide, and melphalan $200 \mathrm{mg} / \mathrm{m}^{2}$ (VDT-Mel). Prior to HSCT, the recipient was seropositive for T. gondii. Antimicrobial prophylaxis consisted of fluconazole, acyclovir, and ciprofloxacin. $\mathrm{He}$ 
developed low-grade fevers, headaches, and impaired memory following engraftment on day +17 after second transplant.

2.2. Diagnostic Workup. A new thalamic lesion with edema and mass effect on the third ventricle and faint peripheral enhancement was found on a contrasted brain magnetic resonance imaging (MRI). Blood cultures were negative. CSF (cerebrospinal fluid) demonstrated elevated protein, normal glucose, and a WBC count $94 / \mu \mathrm{L}$ with predominantly lymphocytes (62) and histiocytes (32). Cytology showed no tumor cells. Cerebrospinal fluid (CSF) demonstrated elevated protein $(245 \mathrm{mg} / \mathrm{dl})$, normal glucose (48 $\mathrm{mg} / \mathrm{dl})$, and a WBC count $94 / \mu \mathrm{L}$ with predominantly lymphocytes $(62 / \mu \mathrm{L})$ and histiocytes $(32 / \mu \mathrm{L})$. Cytology showed no tumor cells. CSF bacterial and fungal cultures, cryptococcal antigen assay, herpes simplex virus, enterovirus, human herpes virus 6, Ebstein-Barr virus, and JC virus polymerase chain reactions (PCRs) were negative. HIV screen (antigen/antibody testing), fungal serologies, and Quantiferon-TB Gold were negative. CSF and serum toxoplasma PCR were positive. The patient was neutropenic $(\mathrm{ANC}<500 / \mu \mathrm{L})$ for approximately seven days following both transplants, but lymphopenia lasted for a prolonged period.

2.3. Treatment. The patient was empirically started on sulfadiazine and pyrimethamine with leucovorin. He developed crystal nephropathy with renal failure while on sulfadiazine and was changed to clindamycin and pyrimethamine for 8 weeks. Response to treatment was favorable at 1-month follow-up, as assessed by clinical and radiological means. Subsequently, he was switched to pyrimethamine, leucovorin, and atovaquone as secondary prophylaxis for toxoplasma infection while he was lymphopenic during ongoing maintenance chemotherapy. The patient died 30 months after HSCT due to progressive myeloma with no evidence of toxoplasmosis.

\section{Discussion}

Toxoplasma gondii infection is usually a result of reactivation of latent infection rather than primary infection with rare exceptions [13]. Pre-HSCT seropositivity is an important risk factor for toxoplasma disease via reactivation in the posttransplant period [14], as in our patient. The markedly low lymphocyte count in our patient likely played a crucial role in the development of infection. Infection was likely a result of the lymphocytotoxic effect of corticosteroid which was a part of the induction and conditioning chemotherapy, the fact that tandem ASCT is more immunosuppressive than a single ASCT, and compromised immune recovery following transplantation.

3.1. Diagnosis. Diagnosing cerebral toxoplasmosis following HSCT is difficult and often necessitates a combination of radiologic techniques, PCR, and histology [15]. Direct detection of the parasite by visualization of tachyzoites by histopathology is a rare event. Diagnosis is most commonly made through detection by PCR [16].

PCR is the most valuable test and can be performed on blood, CSF $[17,18]$, or bronchoalveolar lavage samples, especially in untreated patients. Our patient was diagnosed by positive PCR, performed on serum and cerebrospinal fluid. It has an average sensitivity of $62 \%$, which extends as high as $81 \%$ in untreated patients, but in previously treated patients, its sensitivity is only $20 \%$ [19]. While absolute diagnosis of toxoplasmosis continues to depend on biopsy and demonstration of the pathogen, PCR should be built into the diagnostic strategy before treatment is started, as it offers timely, valuable information and assists in the confirmatory diagnosis of toxoplasma encephalitis and ocular toxoplasmosis [20].

MRI is the most sensitive radiologic technique, typically displaying multiple lesions localized in the basal ganglia and the corticomedullary junction of the cerebral and cerebellar hemispheres [21]. Lesions often show central necrosis and are isointense or hypointense on $\mathrm{T} 1$ and hyperintense on $\mathrm{T} 2$ weighted images. Ring contrast enhancement is variable, depending on the patient's host inflammatory response and immune status with an inverse relationship with the leucocyte level, and it is reduced on corticosteroid treatment [22]. Our patient showed an atypical single lesion with only faint peripheral enhancement likely due to lymphocytopenia and corticosteroid use.

3.2. Treatment. Unlike immunocompetent individuals in whom the infection generally remains latent for life, in HSCT recipients latent toxoplasma infection can reactivate and, if inadequately treated or left untreated, can lead to a fatal outcome [23]. Preemptive treatment using routine blood PCR monitoring appears effective in detecting infection early and preventing disease, especially in seropositive allo-HSCT recipients and high-risk ASCT recipients when chemoprophylaxis is not possible [24]. The gold standard, both in the treatment of reactivation and disease, is the combination of pyrimethamine-sulfadiazine-leucovorin, while trimethoprim-sulfamethoxazole (TMP/SMX) is the agent of choice for primary prophylaxis in high-risk patients $[25,26]$.

Prophylaxis should ideally be started as soon as feasible after allo-HSCT but no later than engraftment and continued for at least six months, as about $10 \%$ of cases occur within one month and $90 \%$ of cases occur during within six months [26]. If engraftment is delayed and TMP/SMX cannot be given due to myelosuppression, atovaquone [27] can be used until engraftment, followed by TMP/SMX. A more controversial issue is the need for prophylaxis in ASCT recipients; such a policy is debatable due to the low incidence of toxoplasmosis in this setting and the consequent lack of experience.

\section{Conclusion}

Toxoplasmosis is an infrequent but serious complication following HSCT and requires a high index of suspicion to implement appropriate diagnostic tests and immediate 
treatment. Because reactivation is the usual mechanism of disease, determining a recipient's pretransplantation serological status for T. gondii is essential. Toxoplasmosis should be considered in the presence of neurological dysfunction even in the absence of typical radiological findings in preASCT toxoplasma seropositive patients. Additional studies are essential to evaluate the efficacy of universal prophylaxis and to determine the role of secondary prophylaxis in highrisk ASCT seropositive patients.

\section{Conflicts of Interest}

The authors declare that there are no conflicts of interest regarding the publication of this paper.

\section{References}

[1] S. V. Rajkumar and S. Kumar, "Multiple myeloma: diagnosis and treatment," Mayo Clinic Proceedings, vol. 91, no. 1, pp. 101-119, 2016.

[2] B. Barlogie, S. Jagannath, K. R. Desikan et al., "Total therapy with tandem transplants for newly diagnosed multiple myeloma," Blood, vol. 93, no. 1, pp. 55-65, 1999.

[3] B. Barlogie, G. J. Tricot, F. van Rhee et al., "Long-term outcome results of the first tandem autotransplant trial for multiple myeloma," British Journal of Haematology, vol. 135, no. 2, pp. 158-164, 2006.

[4] J. A. Child, G. J. Morgan, F. E. Davies et al., "High-dose chemotherapy with hematopoietic stem-cell rescue for multiple myeloma," New England Journal of Medicine, vol. 348, no. 19, pp. 1875-1883, 2003.

[5] C. Busemann, S. Ribback, K. Zimmermann et al., "Toxoplasmosis after allogeneic stem cell transplantation-a single centre experience," Annals of Hematology, vol. 91, no. 7, pp. 1081-1089, 2012.

[6] R. Martino, J. Maertens, S. Bretagne et al., "Toxoplasmosis after hematopoietic stem cell transplantation," Clinical Infectious Diseases, vol. 31, no. 5, pp. 1188-1195, 2000.

[7] M. Nakane, K. Ohashi, J. Tominaga, H. Akiyama, K. Hiruma, and H. Sakamaki, "Disseminated toxoplasmosis after CD34 +-selected autologous peripheral blood stem cell transplantation," Haematologica, vol. 85, no. 3, pp. 334-335, 2000.

[8] S. Yadlapati, D. Dorsky, J. S. Remington et al., "Ocular toxoplasmosis after autologous peripheral-blood stem-cell transplantation," Clinical Infectious Diseases, vol. 25, no. 5, pp. 1255-1256, 1997.

[9] C. S. Straathof, L. M. Kortbeek, H. Roerdink, P. A. E. Sillevis Smitt, and M. J. van den Bent, "A solitary spinal cord toxoplasma lesion after peripheral stem-cell transplantation," Journal of Neurology, vol. 248, no. 9, pp. 814-815, 2001.

[10] M. Lopez-Duarte, A. Insunza, E. Conde, A. Iriondo, F. Mazorra, and A. Zubizarreta, "Cerebral toxoplasmosis after autologous peripheral blood stem cell transplantation," European Journal of Clinical Microbiology \& Infectious Diseases, vol. 22, no. 9, pp. 548-550, 2003.

[11] L. Voegele, A. C. Cheerva, and S. Bertolone, "Cerebral toxoplasmosis after tandem high-dose chemotherapy and autologous hematopoietic cell transplant for neuroblastoma," Journal of Pediatric Hematology/Oncology, vol. 35, no. 2, pp. e50-e52, 2013.

[12] K.-H. Kim, K.-H. Song, J. H. Jeon et al., "A case of cerebral toxoplasmosis following tandem autologous stem cell transplantation in a multiple myeloma patient," Infection and Chemotherapy, vol. 42, no. 3, pp. 181-186, 2010.

[13] M. Osthoff, E. Chew, A. Bajel et al., "Disseminated toxoplasmosis after allogeneic stem cell transplantation in a seronegative recipient," Transplant Infectious Disease, vol. 15, no. 1, pp. E14-E19, 2013.

[14] M. Sumi, F. Aosai, K. Norose et al., "Acute exacerbation of Toxoplasma gondii infection after hematopoietic stem cell transplantation: five case reports among 279 recipients," International Journal of Hematology, vol. 98, no. 2, pp. 214-222, 2013.

[15] J. B. Murat, H. F. Hidalgo, M.-P. Brenier-Pinchart, and H. Pelloux, "Human toxoplasmosis: which biological diagnostic tests are best suited to which clinical situations?," Expert Review of Anti-Infective Therapy, vol. 11, no. 9, pp. 943-956, 2013.

[16] B. Edvinsson, J. Lundquist, P. Ljungman, O. Ringdén, and B. Evengård, "A prospective study of diagnosis of Toxoplasma gondii infection after bone marrow transplantation," APMIS, vol. 116 , no. 5, pp. 345-351, 2008.

[17] K. Mikita, T. Maeda, T. Ono, Y. Miyahira, T. Asai, and A. Kawana, "The utility of cerebrospinal fluid for the molecular diagnosis of toxoplasmic encephalitis," Diagnostic Microbiology and Infectious Disease, vol. 75, no. 2, pp. 155-159, 2013.

[18] L. J. Ryan, P. Ferrieri, and S. E. Pambuccian, "Toxoplasma gondii in the cerebrospinal fluid of a hematopoietic stem cell recipient," Diagnostic Cytopathology, vol. 39, no. 11, pp. 830-831, 2011.

[19] J. M. Costa, C. Pautas, P. Ernault, F. Foulet, C. Cordonnier, and S. Bretagne, "Real-time PCR for diagnosis and follow-up of Toxoplasma reactivation after allogeneic stem cell transplantation using fluorescence resonance energy transfer hybridization probes," Journal of Clinical Microbiology, vol. 38, no. 8, pp. 2929-2932, 2000.

[20] G. Saadatnia and M. Golkar, "A review on human toxoplasmosis," Scandinavian Journal of Infectious Diseases, vol. 44, no. 11, pp. 805-814, 2012.

[21] U. Dietrich, M. Maschke, A. Dörfler, M. Prumbaum, and M. Forsting, "MRI of intracranial toxoplasmosis after bone marrow transplantation," Neuroradiology, vol. 42, no. 1 , pp. 14-18, 2000.

[22] C. N. Kotton, "Zoonoses in solid-organ and hematopoietic stem cell transplant recipients," Clinical Infectious Diseases, vol. 44, no. 6, pp. 857-866, 2007.

[23] A. Conrad, M. Le Maréchal, D. Dupont et al., "A matched case-control study of toxoplasmosis after allogeneic haematopoietic stem cell transplantation: still a devastating complication," Clinical Microbiology and Infection, vol. 22, no. 7, pp. 636-641, 2016.

[24] C. L. Rossi, F. S. Nascimento, S. de Barros-Mazon, D. F. Dias, A. C. Vigorito, and C. A. de Souza, "Serological monitoring of a Toxoplasma infection after hematopoietic stem cell transplantation," Revista do Instituto de Medicina Tropical de São Paulo, vol. 52, no. 4, pp. 225-227, 2010.

[25] F. Derouin and H. Pelloux, "Prevention of toxoplasmosis in transplant patients," Clinical Microbiology and Infection, vol. 14, no. 12, pp. 1089-1101, 2008.

[26] E. Roemer, I. W. Blau, N. Basara et al., "Toxoplasmosis, a severe complication in allogeneic hematopoietic stem cell transplantation: successful treatment strategies during a 5year single-center experience," Clinical Infectious Diseases, vol. 32, no. 1, pp. E1-E8, 2001.

[27] A. Mendorf, E. Klyuchnikov, C. Langebrake et al., "Atovaquone for prophylaxis of toxoplasmosis after allogeneic hematopoietic stem cell transplantation," Acta Haematologica, vol. 134, no. 3, pp. 146-154, 2015. 


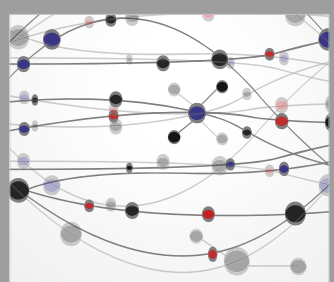

The Scientific World Journal
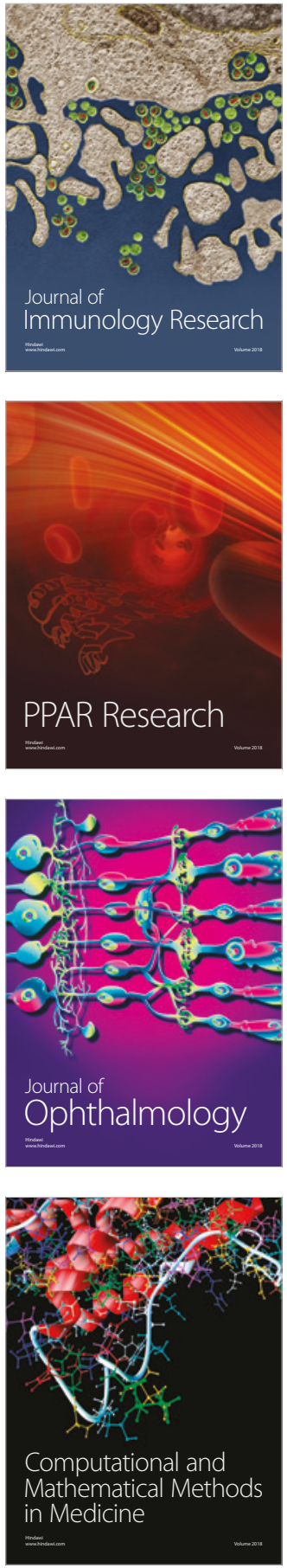

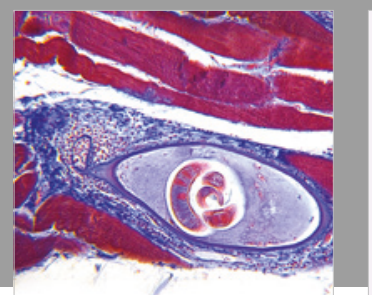

Gastroenterology Research and Practice

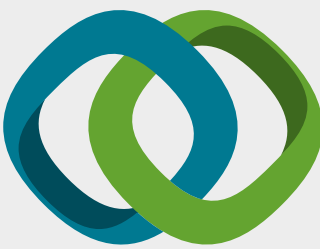

\section{Hindawi}

Submit your manuscripts at

www.hindawi.com
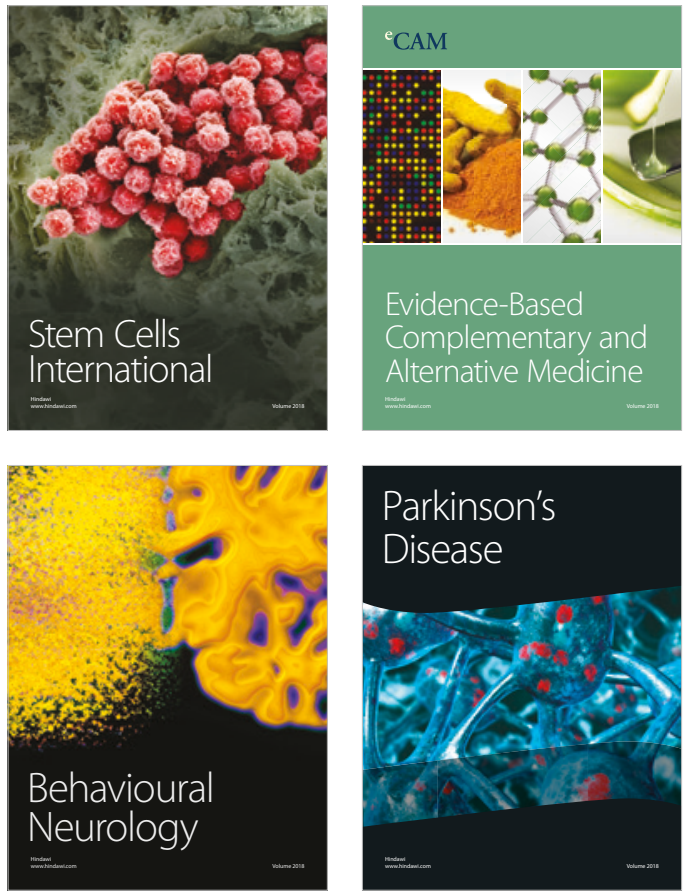

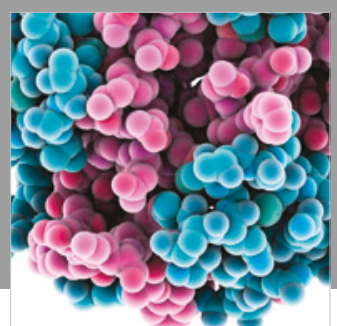

ournal of

Diabetes Research

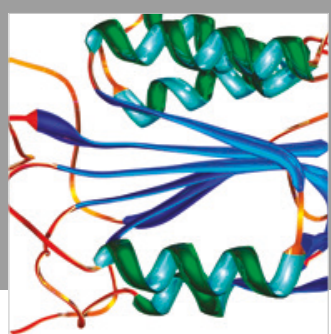

Disease Markers
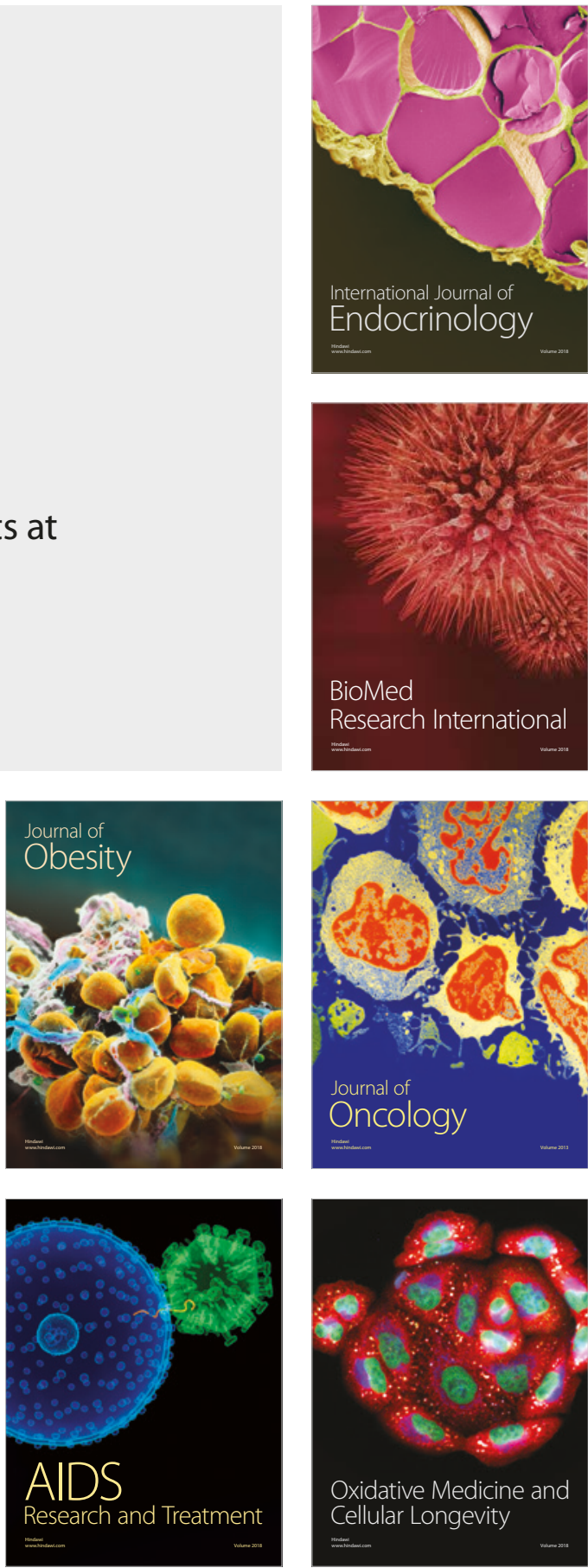